University of South Carolina

Scholar Commons

$2-1-2004$

\title{
Wide-Band/Dual-Band Packaged Antenna for 5-6 GHz WLAN Application
}

\author{
Mohammod Ali \\ University of South Carolina - Columbia, alimo@engr.sc.edu \\ Tuangsit Sittironnarit \\ University of South Carolina - Columbia \\ Huan-Sheng Hwang \\ Sony Ericsson Mobile Communications \\ Robert A. Sadler \\ Sony Ericsson Mobile Communications \\ Gerard James Hayes \\ Sony Ericsson Mobile Communications
}

Follow this and additional works at: https://scholarcommons.sc.edu/elct_facpub

Part of the Electrical and Computer Engineering Commons

\author{
Publication Info \\ Published in IEEE Transactions on Antennas and Propagation, Volume 52, 2004, pages 610-615. \\ http://ieeexplore.ieee.org/xpl/Recentlssue.jsp?punumber=8 \\ (C) 2004 by IEEE
}

This Article is brought to you by the Electrical Engineering, Department of at Scholar Commons. It has been accepted for inclusion in Faculty Publications by an authorized administrator of Scholar Commons. For more information, please contact digres@mailbox.sc.edu. 
suitable to describe the singular behavior of the spatial GF. In its turn in the improved version the analytical part derived in the explicit form provides with this behavior. It can be easily derived from Fig. 2 that the numerical part (dash-point line) of the improved GF gives a considerably smaller contribution in the vicinity of the origin than the analytical one. This numerical part can be calculated with guaranteed accuracy. The real part of the plotted GF is not singular at the origin and its values calculated with and without the analytical extraction coincide.

\section{CONCLUSION}

In this paper, a rigorous way to extract the singularity of the spatial GFs for a sheet electric current over a dielectric coated cylinder is proposed. The spatial GFs are required to analyze cylindrical microstrip antennas. Up to now the direct rigorous numerical calculation of the spatial GFs using the IFT in practice was not possible because of the hidden singularity. The singular part of the spatial GFs is derived in an analytical form. The remaining part of the spatial GFs is calculated numerically with guaranteed accuracy. The proposed spatial GFs can be effectively used in the moment method formulation for cylindrical microstrip antennas. Thus, our approach allows extending the concept of the mixed-potential formulation, which proved its efficiency for planar structures, to cylindrical structures.

\section{REFERENCES}

[1] C. Tokgoz and G. Dural, "Closed-form Green's functions for cylindrically stratified media," IEEE Trans. Microwave Theory Tech., vol. 48, pp. 40-49, Jan. 2000.

[2] R. C. Hall, C. H. Thng, and D. C. Chang, "Mixed-potential Green's function for cylindrical microstrip structures," in Proc. IEEE AP-Symp., 1995, pp. 1776-1779.

[3] N. G. Alexopoulos and A. Nakatani, "Cylindrical substrate microstrip line characterization," IEEE Trans. Microwave Theory Tech., vol. 35, pp. 843-849, Sept. 1987.

[4] T. M. Habashy, S. M. Ali, and J. A. Kong, "Input impedance and radiation pattern of cylindrical-rectangular and wraparound microstrip antennas," IEEE Trans. Antennas Propagat., vol. 38, pp. 722-731, May 1990.

[5] G. A. E. Vandenbosch and A. R. Van de Capelle, "Mixed-potential integral expression formulation of the electric field in a stratified dielectric medium - Application to the case of a probe current source," IEEE Trans. Antennas Propagat., vol. 40, pp. 806-817, July 1992.

[6] M. Abramowitz and I. A. Stegun, Handbook of Mathematical Functions. New York: Dover, 1971.

[7] Gradshteyn and I. Ryzhik, Table of Integrals, Series and Products. New York: Academic Press, 1980.

\section{Wide-Band/Dual-Band Packaged Antenna for 5-6 GHz WLAN Application}

\author{
M. Ali, T. Sittironnarit, H.-S. Hwang, R. A. Sadler, and G. J. Hayes
}

Abstract-A wide-band/dual-band packaged antenna is proposed for wireless local-area network (WLAN) applications in the $5.15-5.35 \mathbf{~ G H z}$ and 5.725-5.825 GHz frequency range. The antenna is internal to the housing of a personal digital assistant, such as a Palm organizer, and has the dimensions of 28 by 9 by $3 \mathrm{~mm}$ on an FR4 substrate. The antenna meets or exceeds the bandwidth requirements for the dual-band IEEE 802.11a WLAN applications $(5.15-5.35 \mathrm{GHz}$ and $5.725-5.825 \mathrm{GHz})$ within 2:1 voltage standing-wave ratio.

Index Terms-Antenna, dual-band, packaged, wide-band, wireless local-area network (WLAN).

\section{INTRODUCTION}

The rapid growth of wireless communications has necessitated that antennas for portable devices be low profile, packaged, and wide-band to allow operation at multiple frequency bands, eliminating the need for separate antennas for each application. Examples of packaged antennas can be found in [1]-[5]. Recently there has been a lot of interest in terms of packaged antennas for Bluetooth and wireless local-area network (WLAN) applications [6]-[9].

In this paper we present a wide-band packaged antenna that can support the IEEE 802.11a wireless local-area network bands (5.15-5.35 $\mathrm{GHz}$ and $5.725-5.825 \mathrm{GHz}$ ). The configuration is similar to those presented in [10] and [11]. In [10] only a single band folded design was presented for Bluetooth application (2.4-2.485 GHz, 3.5\% bandwidth). No method of wide-band/dual-band operation was described.

In contrast we present a wide-band/dual-band folded design. Our proposed packaged design can either be used as a wide-band antenna that can provide bandwidths in excess of $10 \%$ within 2:1 voltage standing-wave ratio (VSWR) or be used for dual-band operation where the bands are separated by 500 to $700 \mathrm{MHz}$ in the $5-6 \mathrm{GHz}$ band. This latter property has been exploited to present a design that satisfies the IEEE 802.11a WLAN 5.15-5.35 GHz and 5.725-5.825 $\mathrm{GHz}$ bands. The antenna design presented here is packaged within the housing of a personal digital assistant (PDA) and has the maximum dimensions of 28 by 9 by $3 \mathrm{~mm}$. The wide-band/dual-band operation has been achieved through proximity parasitic coupling between a folded radiator and an extended PCB (printed circuit board) ground plane. The dimensions of the extended PCB ground plane have been appropriately adjusted to ensure the desired coupling. This coupling mechanism is similar to those presented in our prior work [12], [13]. The proposed antenna has been simulated for current distribution,
Manuscript received July 23, 2002; revised March 29, 2003.

M. Ali and T. Sittironnarit are with the Department of Electrical Engineering, University of South Carolina, Columbia, SC 29208 USA (e-mail: alimo@engr.sc.edu).

H.-S. Hwang, R. A. Sadler, and G. J. Hayes are with Sony Ericsson Mobile Communications, Research Triangle Park, NC 27709 USA.

Digital Object Identifier 10.1109/TAP.2004.823992 


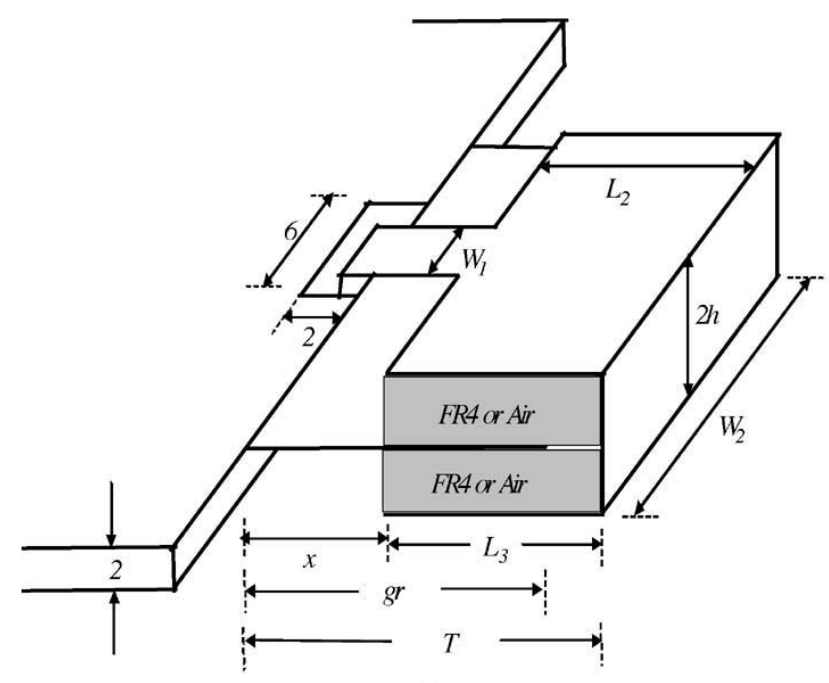

(a)

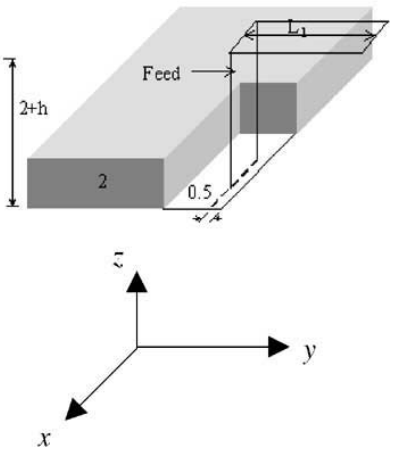

(b)

Fig. 1. (a) Geometry of proposed antenna and (b) feed arrangement.

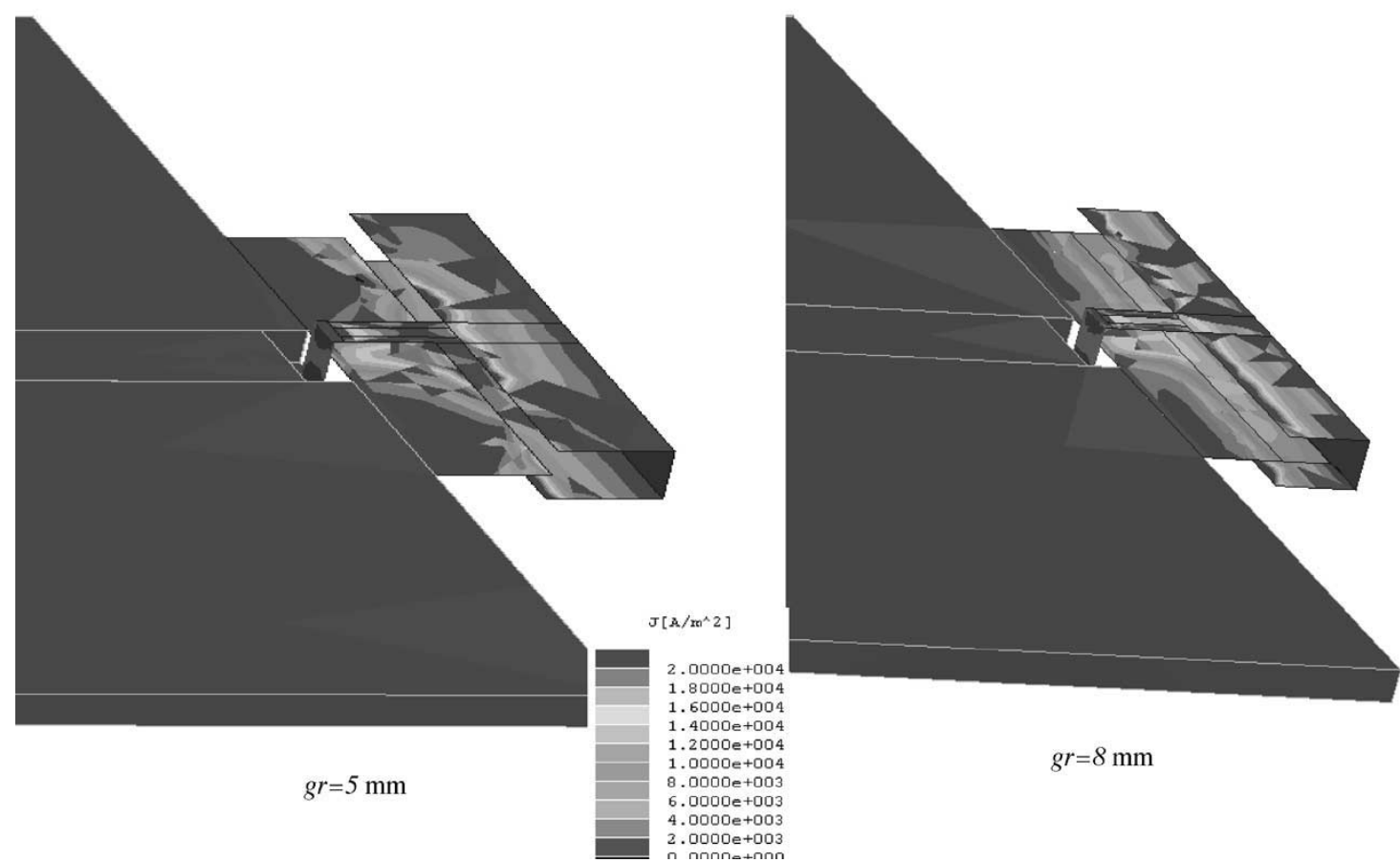

Fig. 2. Computed current density distribution at $5.775 \mathrm{GHz}$. Antenna parameters are $w_{1}=2 \mathrm{~mm}, w_{2}=28 \mathrm{~mm}, L_{1}=4.5 \mathrm{~mm}, L_{2}=L_{3}=5 \mathrm{~mm}, \varepsilon_{\mathrm{r}}=4.7$, $\mathrm{x}=4 \mathrm{~mm}, \mathrm{~T}=9 \mathrm{~mm}$, and $2 h=3 \mathrm{~mm}$.

input impedance, and VSWR using HFSS. ${ }^{1}$ Experimental data consisting of VSWR, gain, and radiation pattern are also given.

Further widening of bandwidth can be obtained by using foam or air layers instead of FR4. In such a case the antenna dimensions are 50 by 22 by $3 \mathrm{~mm}$ and the bandwidth obtained is $15.5 \%$ within $2: 1$ VSWR. Increasing the antenna height to $4 \mathrm{~mm}$ increases the bandwidth $18.0 \%$.

\section{ANTENNA CONFIGURATION}

The geometrical configuration of the proposed packaged antenna is shown in Fig. 1. The folded antenna can be printed on FR4 or it can be manufactured to operate in air. Both cases have been investigated. The

${ }^{1}$ HFSS, Ansoft Corporation: http://www.ansoft.co.jp/hfss.htm. dimensions of the PCB are 120 by 80 by $2 \mathrm{~mm}$. The longer dimension of the antenna is along the $x$ axis while the shorter dimension is along the $y$ axis. More detailed information about the antenna feed can be obtained from Fig. 1(b). Note that the top PCB ground has been extended so that it is positioned in the middle of both layers of the antenna. This extended ground layer when coupled with the driven element results in wide-band characteristic.

\section{COMPuTATIONAL RESUlts}

\section{A. Antenna Printed on FR4}

Fig. 2 shows the current distribution for the antenna for variations in $g r$. We can clearly observe that as $g r$ changes from 5 to $8 \mathrm{~mm}$, the 


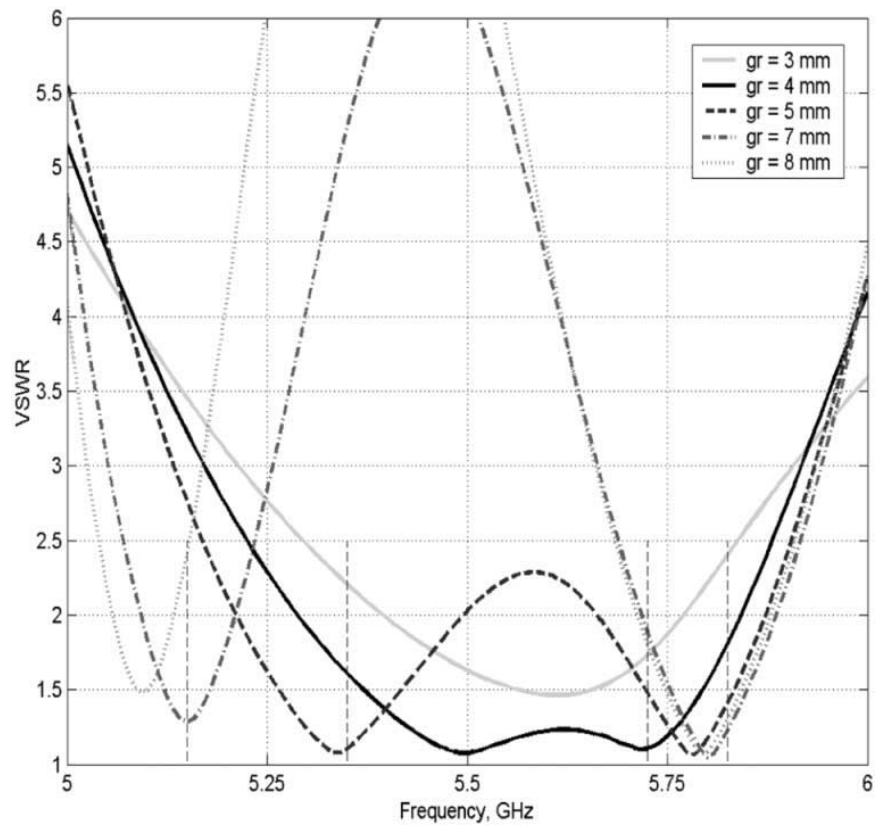

Fig. 3. Computed VSWR versus frequency with $g r$ as the parameter when $w_{1}=2 \mathrm{~mm}, w_{2}=28 \mathrm{~mm}, L_{1}=4.5 \mathrm{~mm}, L_{2}=L_{3}=5 \mathrm{~mm}, \varepsilon_{\mathrm{r}}=4.7, \mathrm{x}=4 \mathrm{~mm}$, $\mathrm{T}=9 \mathrm{~mm}$, and $2 h=3 \mathrm{~mm}$.
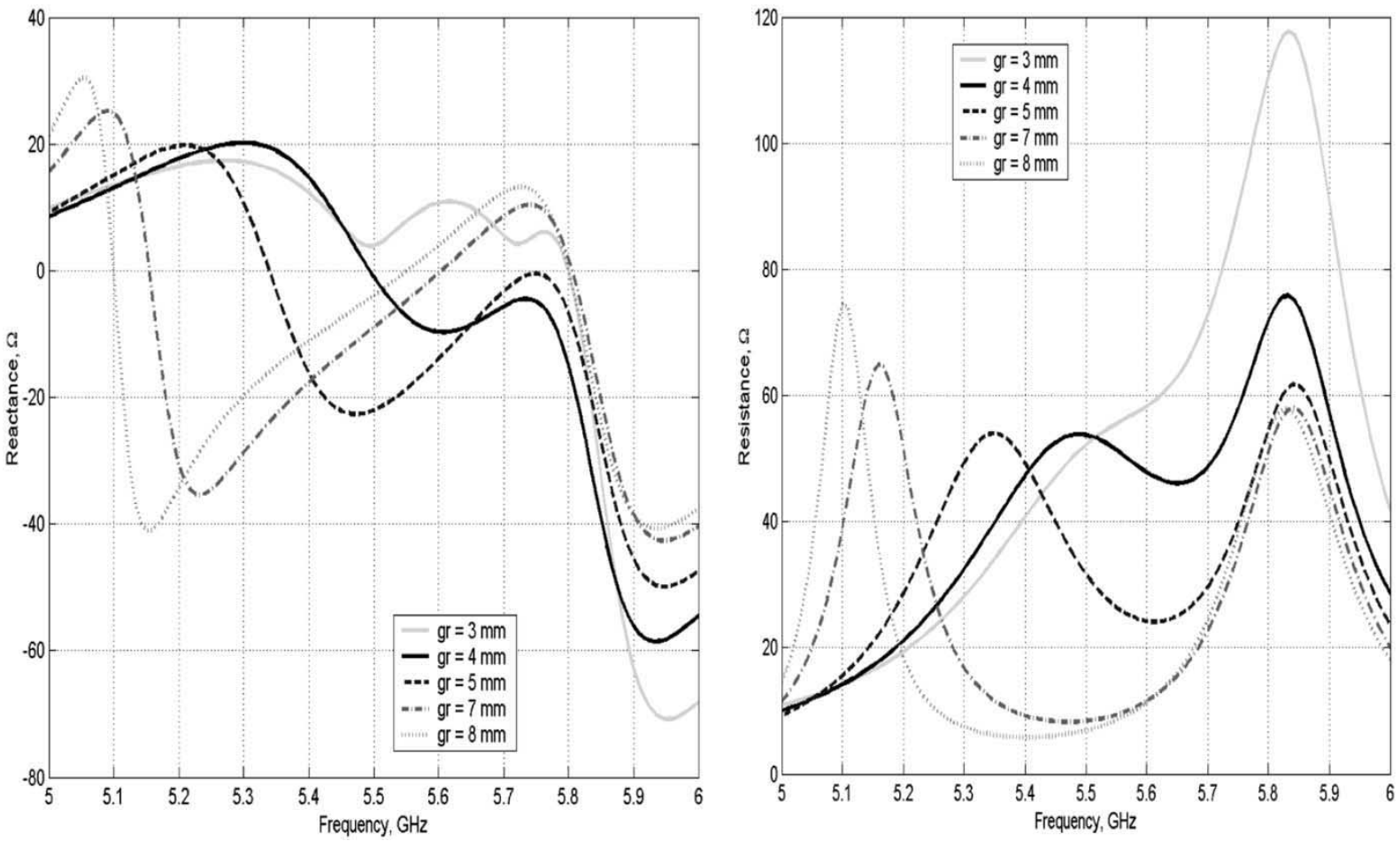

Fig. 4. Computed input impedance versus frequency with $g r$ as the parameter when $w_{1}=2 \mathrm{~mm}, w_{2}=28 \mathrm{~mm}, L_{1}=4.5 \mathrm{~mm}, L_{2}=L_{3}=5 \mathrm{~mm}, \varepsilon_{\mathrm{r}}=4.7$, $\mathrm{x}=4 \mathrm{~mm}, \mathrm{~T}=9 \mathrm{~mm}$, and $2 h=3 \mathrm{~mm}$.

intensity of current increases particularly in the overlap region between the radiating element and the extended ground plane. This indicates the presence of coupling between the radiating element and the extended ground plane, which increases in intensity as $g r$ increases even further.

Computed VSWR versus frequency data as function of the overlap function $g r$ is shown in Fig. 3. Clearly for $g r=3 \mathrm{~mm}$, coupling between the radiating element and the extended ground plane is minimal since the overlap region is $-1 \mathrm{~mm}$. As $g r$ increases to $4,5,7$, and 8 $\mathrm{mm}$, coupling increases and the antenna starts to show wide-band or dual-band characteristics. For $g r=4 \mathrm{~mm}$, the antenna has bandwidth of $10 \%$ within $2: 1 \mathrm{VSWR}$. Increasing $g r$ from 4 to $5 \mathrm{~mm}$ transforms a wide-band antenna into a dual-band one [see Fig. 3]. Thus the antenna can easily satisfy the IEEE 802.11 a bands $5.15-5.35 \mathrm{GHz}$ and $5.725-5.825 \mathrm{GHz}$. Further increase in $g r$ to 7 or $8 \mathrm{~mm}$ reduces the 


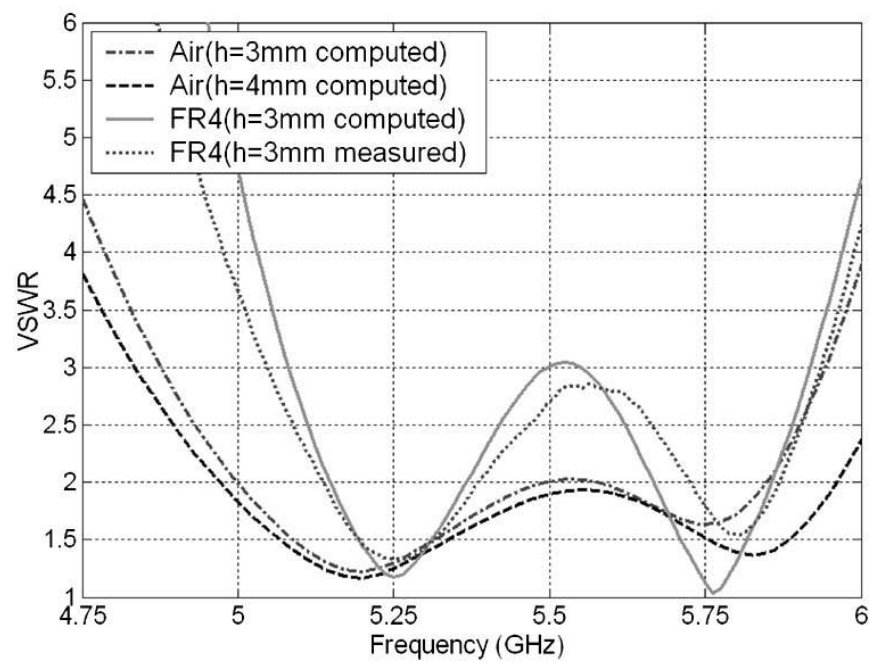

Fig. 5. Computed and measured VSWR versus frequency of the proposed antenna. Antenna on FR 4 has dimensions $w_{1}=2.6 \mathrm{~mm}, w_{2}=28 \mathrm{~mm}, L_{1}=4.5 \mathrm{~mm}$, $L_{2}=L_{3}=5 \mathrm{~mm}, g r=5 \mathrm{~mm}, \varepsilon_{\mathrm{r}}=4.7$, and $2 \mathrm{~h}=3 \mathrm{~mm}$; first antenna on air has dimensions $W_{1}=50 \mathrm{~mm}, h=3 \mathrm{~mm}, L_{1}=11.75 \mathrm{~mm}, g r=13 \mathrm{~mm}$, $W_{2}=16.2 \mathrm{~mm}$, and $L_{2}=L_{3}=5.5 \mathrm{~mm}$; second antenna on air has dimensions $W_{1}=50 \mathrm{~mm}, h=4 \mathrm{~mm}, L_{1}=11.5 \mathrm{~mm}, \mathrm{gr}=14 \mathrm{~mm}, W_{2}=16.2 \mathrm{~mm}$, and $L_{2}=L_{3}=5.5 \mathrm{~mm}$.

low-band resonance frequency even further, which may be useful for some other dual-band applications where the band separation is larger.

The bandwidth performance of the antenna can be better understood from the impedance characteristics of Fig. 4 . Note that for $g r=3 \mathrm{~mm}$ the antenna only exhibits one resonance at $5.8 \mathrm{GHz}$. The reactance varies from 5 to $15 \Omega$ for the frequency range of 5 to $5.7 \mathrm{GHz}$. At around $5.5 \mathrm{GHz}$ the resistance is close to $50 \Omega$, which provides the antenna a better match. As $g r$ increases to $4 \mathrm{~mm}$ the antenna shows two distinct resonances and the resistance varies between 40 and $60 \Omega$ from 5.35 to $5.75 \mathrm{GHz}$. In addition the midband resistance is about $50 \Omega$, which results in the wide-band characteristic shown in Fig. 2. As $g r$ increases to $7 \mathrm{~mm}$ or higher, the antenna still has good resistance at two bands to make it dual-band. However, the midband resistance is too low (about $10 \Omega$ ), resulting in high VSWR.

\section{B. Antenna in Air}

The proposed antenna can also be manufactured to operate in air. In such a case manufacturing the antenna should be much simpler and easier. The proposed folded antenna in air was simulated using HFSS. Antenna dimensions were adjusted to achieve optimum performance in the designated frequency bands (5-6 GHz). Computed VSWR data for antenna on FR4 and in air are shown in Fig. 5. Bandwidth obtained is $15.5 \%$ with $3 \mathrm{~mm}$ antenna height and $18.0 \%$ with $4 \mathrm{~mm}$ antenna height (within VSWR of 2:1). In contrast, bandwidth obtained with FR4 was $10 \%$ with $3 \mathrm{~mm}$ antenna height (within VSWR of 2:1). Thus wider bandwidth can be obtained by replacing FR4 with air. However, the dimensions of the antenna in air are about 50 by 22 by $3 \mathrm{~mm}$ while those on FR 4 are 28 by 9 by $3 \mathrm{~mm}$.

\section{Measured Results}

A laboratory prototype of the proposed antenna (on FR4) was built and tested for VSWR. Measured and computed VSWR data are compared in Fig. 5. The agreement between the measured and computed data is quite good. Computed and measured resonant frequencies are about the same. The measured bandwidths in both bands are also in good agreement with the computed bandwidths within 2:1 VSWR. It is clear that the antenna satisfies the bandwidth requirements for the IEEE 802.11a LAN (5.15-5.35 GHz and 5.725-5.825 GHz). The midband VSWR is only as high as 2.7:1.
TABLE I

Measured Peak Gain Data for the Proposed Antenna (FreE-Space) AT 5.25 AND $5.78 \mathrm{GHz}$. FOR PATTERN CHARACTERISTICS AND BEAM PEAK LOCATIONS FOR $y z$-AND $x y$-PLANES SEE FIG. 6

\begin{tabular}{c|c|c}
\hline Frequency (GHz) & Peak gain (dBi), yz-plane & Peak gain (dBi), xy-plane \\
\hline 5.25 & 1.8 at $\theta=0^{\circ}$ & -0.5 at $\theta=210^{\circ}$ \\
\hline 5.78 & $0.8 \mathrm{dBi}$ at $\theta=140^{\circ}$ & $0.6 \mathrm{dBi}$ at $\theta=190^{\circ}$ \\
\hline
\end{tabular}

Antenna radiation pattern and gain were measured inside an anechoic chamber. Measured gain for the two principal plane patterns are listed in Table I. The free-space peak gain at $5.25 \mathrm{GHz}$ is $1.8 \mathrm{dBi}$, while that at $5.78 \mathrm{GHz}$ is $0.8 \mathrm{dBi}$. Measured radiation patterns at $5.25 \mathrm{GHz}$ are shown in Fig. 6(a), (b), and (e). In the $x y$ plane [Fig. 6(a)], the vertical component is the dominant one with the peak of the beam directed toward $-150^{\circ}$. In the $x z$ plane pattern [Fig. 6(b)], the vertical component is the dominant one with the peak of the beam directed toward $0^{\circ}$. In the $y z$ plane [Fig. 6(e)], the horizontal component is the dominant one with its peak along $\theta=0^{\circ}$.

Measured normalized radiation patterns at $5.78 \mathrm{GHz}$ are shown in Fig. 6(c), (d), and (f). The $x y$ plane patterns shown in Fig. 6(c) indicate that the vertical component is the dominant field component. The combined pattern looks somewhat directional. In the $x z$ plane [Fig. 6(d)], while the horizontal component is the stronger one, the vertical component is also reasonably strong. Thus the combined strength of these two components will result in a uniform field strength variation along this plane. In the $y z$ plane [Fig. 6(f)] pattern the horizontal component has a nearly uniform variation with an average value of at least $-5 \mathrm{~dB}$. Only at one narrow angular region $\left(95\right.$ to $\left.110^{\circ}\right)$ the field intensity goes down to $-10 \mathrm{~dB}$.

\section{CONCLUSION}

A wide-band/dual-band packaged antenna has been analyzed and designed to support the IEEE 802.11a wireless LAN platform (5.15-5.35 $\mathrm{GHz}$ and $5.725-5.825 \mathrm{GHz}$ ). It has been shown that by adjusting the coupling between the extended ground plane of the PCB and the 


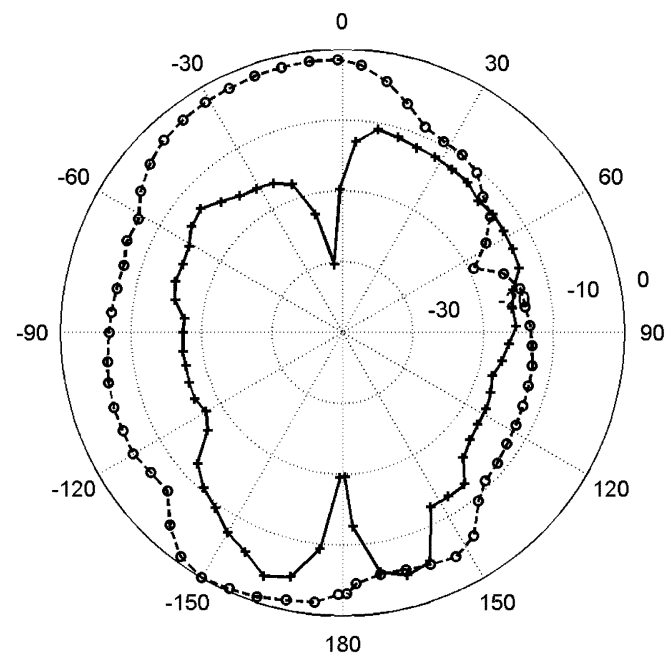

(a)

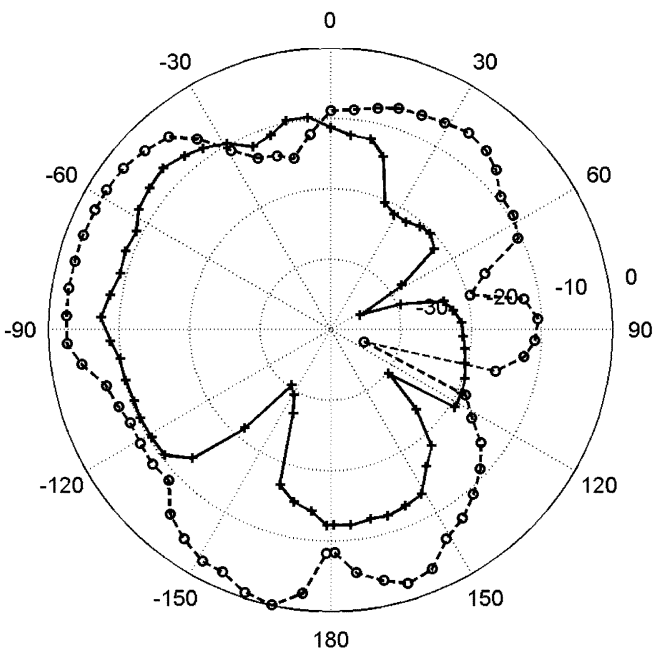

(c)

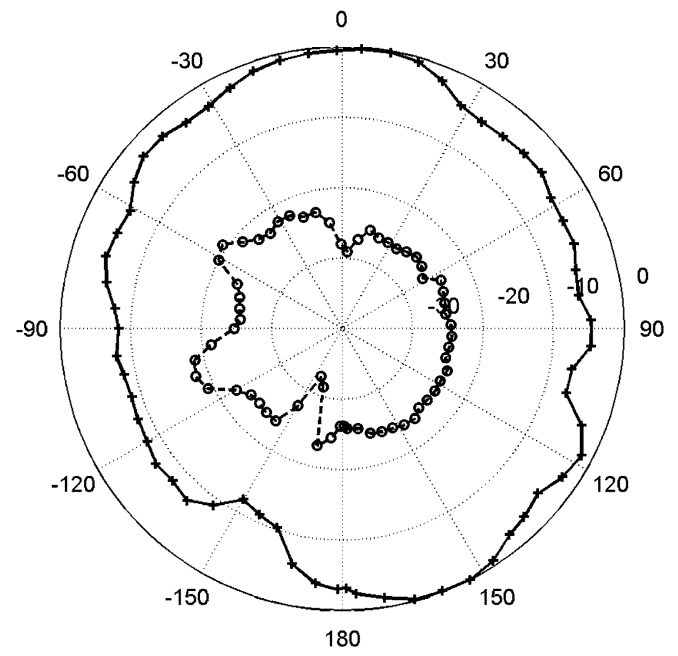

(e)

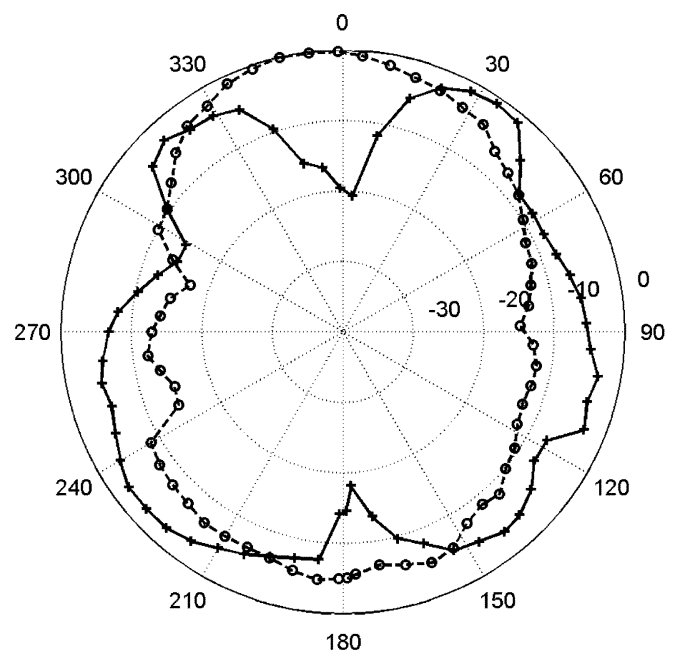

(b)

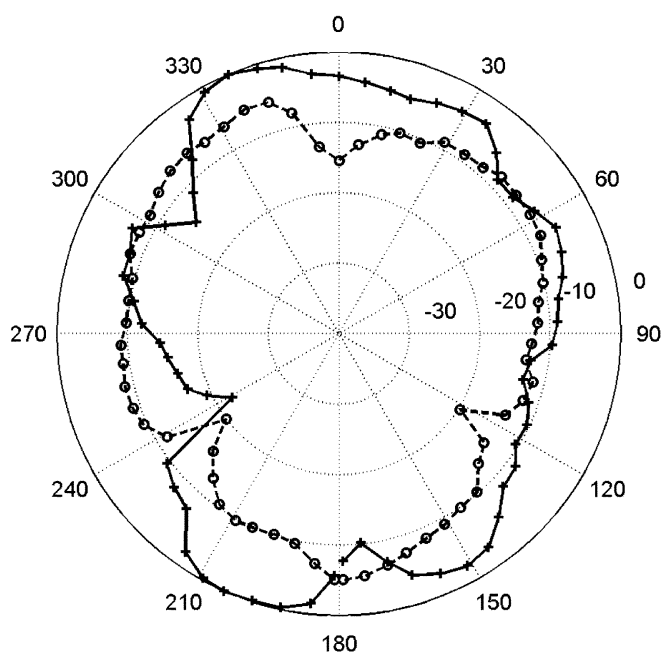

(d)

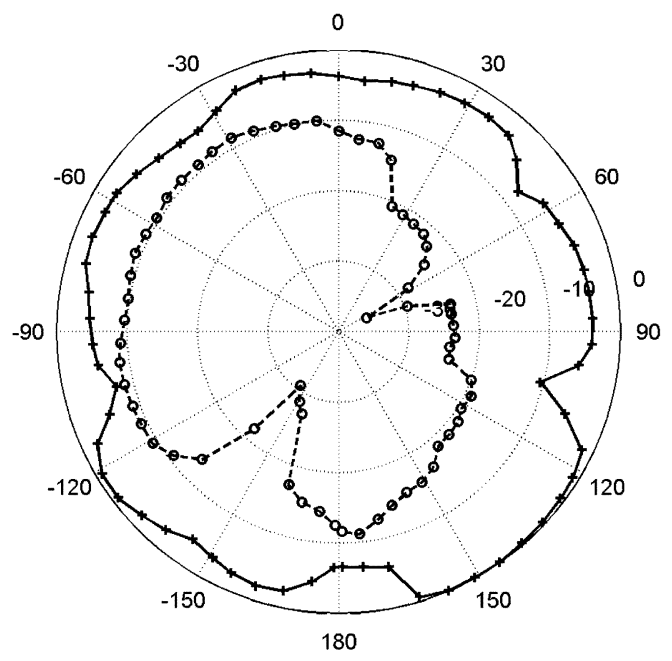

(f)

Fig. 6. Measured normalized radiation patterns at (a) $5.25 \mathrm{GHz} x y$ plane, (b) $5.25 \mathrm{GHz} x z$ plane, (c) $5.78 \mathrm{GHz} x y$ plane, (d) $5.78 \mathrm{GHz} x z$ plane, (e) $5.25 \mathrm{GHz}$ $y z$ plane, and (f) $5.78 \mathrm{GHz} y z$ plane. Antenna parameters are $w_{1}=2.6 \mathrm{~mm}, w_{2}=28 \mathrm{~mm}, L_{1}=4.5 \mathrm{~mm}, L_{2}=L_{3}=5 \mathrm{~mm}, \varepsilon_{\mathrm{r}}=4.7$, and $2 h=3 \mathrm{~mm}$. Solid line: horizontal component; dotted line: vertical component.

antenna, the operational frequency and bandwidth can be changed. Either a distinct dual-band response or a single wide-band response is achievable. The antenna was fabricated on an FR4 substrate and measured for VSWR, gain, and radiation pattern. 


\section{REFERENCES}

[1] K. L. Virga and Y. Rahmat-Samii, "Low-profile enhanced-bandwidth PIFA antennas for wireless communications packaging," IEEE Trans. Microwave Theory Tech., vol. 45, pp. 1879-1888, Oct. 1997.

[2] G. K. H. Lui and R. D. Murch, "Compact dual-frequency PIFA designs using LC resonators," IEEE Trans. Antennas Propagat., vol. 49, pp. 1016-1019, July 2001.

[3] M. Ali, G. J. Hayes, H.-S. Hwang, and R. A. Sadler, "Design of a multi-band internal antenna for third generation mobile phone handsets," IEEE Trans. Antennas Propagat., vol. 51, pp. 1452-1461, July 2003 , to be published.

[4] M. Ali, R. A. Sadler, and G. J. Hayes, "A uniquely packaged internal inverted-F antenna for bluetooth or wireless LAN application," IEEE Antennas Wireless Propagat. Lett., vol. 1, no. 1, pp. 5-7, 2002.

[5] M. Ali and G. J. Hayes, "A small printed integrated inverted-F antenn for bluetooth application," Microwave Opt. Technol. Lett., vol. 33, no. 5, pp. 347-349, June 5, 2002.

[6] S.-H. Yeh and K.-L. Wong, "Dual-band F-shaped monopole antenna for 2.4/5.2 GHZ WLAN applications," in IEEE AP-S Int. Symp. Dig., vol. 4, 2002, pp. 72-75.

[7] F.-R. Hsiao, J.-S. Kuo, T. W. Chiou, and K.-L. Wong, "A broadband very-high-permittivity dielectric resonator antenna for WLAN application in the $5.2 \mathrm{GHz}$ band," Microwave Opt. Technol. Lett., vol. 32, no. 6, pp. 426-427, 2002.

[8] N. Boisbouvier, F. L.F. Le Bolzer, and A. Louzir, "A compact radiation pattern diversity antenna for WLAN applications," in IEEE AP-S Int. Symp. Dig., vol. 4, 2002, pp. 64-67.

[9] X. Qing and M. Y. W. Chia, "Broadband annular dual-slot antenna for WLAN applications," in IEEE AP-S Int. Symp. Dig., vol. 2, 2002, pp. $452-455$.

[10] A. Faraone and D. O. McCoy, "The folded patch omnidirectional antenna," in IEEE AP-S Int. Symp. Dig., vol. 2, 2001, pp. 712-715.

[11] C. G. Christodoulou, P. F. Wahid, M. R. Mahbub, and M. C. Bailey, "Design of a minimum-loss series-fed foldable microstrip," IEEE Trans. Antennas Propagat., vol. 48, pp. 1264-1267, Aug. 2000.

[12] M. Ali, S. S. Stuchly, and K. Caputa, "A wide-band dual meandersleeve antenna," J. Electromagn. Waves Applicat., vol. 10, no. 9, pp. $1223-1236,1996$

[13] M. Ali, "Dual-band antenna having mirror image meandering segments and wireless communicators incorporating same," U.S. Patent 6184 836, Feb. 6, 2001

\section{Computation of Input Impedance of Printed Antennas With Finite Size and Arbitrarily Shaped Dielectric Substrate and Ground Plane}

\author{
Cai-Cheng $\mathrm{Lu}$ and Chun $\mathrm{Yu}$
}

\begin{abstract}
The input impedances of a microstrip antenna with finite and curved substrates are calculated using the hybrid volume surface integral equation approach. The results for flat and large substrate cases are compared with the measurement as well as the method of moment solution based on the spectral domain Green's function for infinitely large ground plane. Numerical results show that the input impedance can be significantly influenced when the substrate of a patch antenna is reduced in size or curved in shape.
\end{abstract}

Index Terms-Input impedance, integral equations, microstrip antenna.

\section{INTRODUCTION}

Analytical and full-wave numerical approaches have been widely used in the analysis, design, and prototyping of many printed antennas.

Manuscript received May 10, 2002; revised February 15, 2003. This work was supported in part by the National Science Foundation (NSF) under award ECS-0093692, and in part by the Office of Naval Research (ONR) under award N00014-00-1-0605.

The authors are with the Department of Electrical Engineering, University of Kentucky, Lexington, KY 40506 USA (e-mail: cclu@engr.uky.edu).

Digital Object Identifier 10.1109/TAP.2004.823894
Typical methods for printed structure analysis include the method of moments (MoM), the finite-difference time-domain method (FDTD), the finite element method (FEM), and the transmission line method (TLM). Those that are based on the integral equation methods have relied on the layered media Green's function, and hence are limited to infinitely large and flat dielectric substrates and ground plane. In practical applications, accurate results can be achieved when the substrate size (as well as the ground size) is much larger than that of the printed structures, and the radii of curvatures of the ground plane are much larger than the wavelength. It is generally understood that when the substrate edge is close to that of the printed patch, the input impedance will not be accurate if the integral equation approach with layered media Green's function is used. This is due to the fact that the interaction of the printed patch and the substrate edge is strong and this interaction is not accounted for in the layered media Green's function. Efforts have been made in various previous works [1]-[3] to model printed structures with finite size substrate. In [1], Sarkar and Arvas presented a hybrid volume-surface integral equation formulation to calculate the radiation pattern of various microstrip antennas with finite ground plane. However no input impedance calculation was made in that paper. In [2], Sheng, Yung, and Chan used the hybrid finite-element and the boundary integral equation method to study the effect of the finite and curved substrate on a microstrip transmission line. They presented the calculated current magnitude on the microstrip when the radius of the curvature varied. It has been reported in [2] that the current magnitude will be significantly different for the case of flat substrate and the curved substrate, and the propagation constant and the attenuation coefficient will also vary with the radius of curvature of the substrate.

In this paper, we present a hybrid volume-surface integral equation (VSIE) approach to investigate the effect of the curvature and the size of the substrate/ground plane on the input impedance of microstrip antennas. Compared with previous simulation approaches of printed structures, the VSIE approach presents a number of advantages: 1) Unlike the differential equation solvers such as the finite-difference time-domain method and the finite-element method [4]-[6], this approach is based on integral equation that does not need extra grid points to terminate the solution domain. It only meshes the physical structure (conducting surface and dielectric volume). 2) Unlike the surface integral equation approaches for layered media problems [5]-[7] which assumes flat and infinite substrate and ground plane, this approach includes the dielectric and ground plane into the solution domain, and the free-space Green's function is used to formulate the problem. Hence, it gives flexibility to model structures of real size and of nonflat, arbitrarily shaped substrate and ground planes. This is especially of interest to model a realistic system board that contains printed devices as well as supporting and mounting structures (either conductors or dielectrics). 3) Because the free-space Green's function is used in the formulation, this VSIE approach can be integrated to the multilevel fast multipole algorithm so that electrically large structures can be modeled.

In the followings, we first describe the formulation of the VSIE approach in Section II, and then present numerical examples in Section III to a) verify our calculation results with that of published measurements and calculations for flat and large size substrate, and b) to show the influence of the finite substrate size and curved substrate shape on the input impedances of patch antennas. The formulation is in frequency domain and the time factor of $\exp \{-i \omega t\}$ is suppressed from the equations. It should be pointed out that it is not necessary for the presented VSIE approach to restrict the size and shape of the ground plane and substrate, for the simplicity of illustration, this paper assumes that the ground plane is attached to the bottom face of the substrate so that the ground plane and the substrate have the same size and shape. 